\title{
APROKSIMASI FUNGSI KONTINU TERBATAS DENGAN KONVOLUSI
}

\author{
Elin Herlinawati \\ Fakultas Sains dan Teknologi, Universitas Terbuka \\ e-mail: elin@ecampus.ut.ac.id
}

\begin{abstract}
Convolution is a mathematical operation on two functions that produces a new function that can be seen as a modified version of one of its original functions. The convolution operator has no identity element. However, it has an approximate identity. It can be found as a sequence of $g_{k}$ such that convolution of $f$ and $g_{k}$ converges to $f$ for $k \rightarrow \infty$. It implies that convolution can be used to approximate a function. In this article, we have proven basic theorems about approximation function by convolution for a bounded function in $C\left(\mathbb{R}^{d}\right)$.

Keywords: approximation, bounded continuous functions, convolution
\end{abstract}

\begin{abstract}
ABSTRAK
Konvolusi adalah suatu operasi pada dua fungsi dan menghasilkan suatu fungsi baru yang dapat dipandang sebagai versi modifikasi dari salah satu fungsi aslinya. Operasi konvolusi tidak memiliki unsur identitas. Namun, operasi konvolusi memiliki identitas hampiran, yakni dapat ditemukannya suatu barisan fungsi $g_{k}$ sehingga konvolusi dari $f$ dan $g_{k}$ konvergen ke $f$ untuk $k \rightarrow \infty$. Hal ini mengakibatkan konvolusi dapat digunakan untuk aproksimasi fungsi. Pada artikel ini dibuktikan teorema-teorema yang mendasari aproksimasi fungsi dengan konvolusi bagi fungsi terbatas di $C\left(\mathbb{R}^{d}\right)$.
\end{abstract}

Kata kunci: aproksimasi, fungsi kontinu terbatas, konvolusi 
Konvolusi merupakan operasi matematika pada dua fungsi yang menghasilkan suatu fungsi baru dan dapat dipandang sebagai versi modifikasi dari salah satu fungsi aslinya.

Definisi 1 (Gunawan, 2017). Misalkan $f$ dan $g$ merupakan fungsi-fungsi yang terdefinisi pada $\mathbb{R}^{d}$, maka konvolusi dari $f$ dan $g$ didefinisikan sebagai

asalkan integral ini konvergen.

$$
(f * g)(x)=\int_{\mathbb{R}^{d}} f(y) g(x-y) d y
$$

Definisi 1 juga analog dengan definisi yang disebutkan oleh Folland (1992) dan Stein (2003). Lebih jauh, Definisi 1 menyebutkan bahwa syarat suatu konvolusi dari dua buah fungsi ada jika integral dari hasil kali dua fungsi tersebut sepanjang $\mathbb{R}^{d}$ ada dan berhingga. Selanjutnya, untuk menunjukkan hal tersebut, perhatikan beberapa kasus berikut.

(i) Jika $f \in L^{1}\left(\mathbb{R}^{d}\right)$ dan $g \in L^{\infty}\left(\mathbb{R}^{d}\right)$, maka $|g(x)| \leq M$ hampir dimana-mana sehingga

$$
|(f * g)(x)|=\left|\int_{\mathbb{R}^{d}} f(y) g(x-y) d y\right| \leq M \int_{\mathbb{R}^{d}} f(y) d y<\infty
$$

hampir dimana-mana. Dengan kata lain, $f * g \in L^{\infty}\left(\mathbb{R}^{d}\right)$. Sebaliknya, jika $f \in$ $L^{\infty}\left(\mathbb{R}^{d}\right)$ dan $g \in L^{1}\left(\mathbb{R}^{d}\right)$, maka $|f(x)| \leq N$ hampir dimana-mana sehingga

$$
|(f * g)(x)|=\left|\int_{\mathbb{R}^{d}} f(x-y) g(y) d y\right| \leq N \int_{\mathbb{R}^{d}} g(y) d y<\infty
$$

hampir dimana-mana. Jadi, $f * g \in L^{\infty}\left(\mathbb{R}^{d}\right)$ ada dan $f * g \in L^{\infty}\left(\mathbb{R}^{d}\right)$.

(ii) Jika $f, g \in L^{2}\left(\mathbb{R}^{d}\right)$, maka

$$
\begin{aligned}
|(f * g)(x)|=\left|\int_{\mathbb{R}^{d}} f(y) g(x-y) d y\right| & \leq\left(\int_{\mathbb{R}^{d}}|f(y)|^{2} d y\right)^{\frac{1}{2}}\left(\int_{\mathbb{R}^{d}}|g(x-y)|^{2} d y\right)^{\frac{1}{2}} \\
& =\|f\|_{2}\|g\|_{2}<\infty
\end{aligned}
$$

Hal ini menunjukkan bahwa $f * g$ ada.

(iii) Jika $f, g \in L^{1}\left(\mathbb{R}^{d}\right)$, maka fungsi $y \rightarrow f(y) g(x-y)$ ada di $L^{1}\left(\mathbb{R}^{d}\right)$ untuk hampir setiap $x \in \mathbb{R}^{d}, f * g \in L^{1}\left(\mathbb{R}^{d}\right)$, dan

$$
\|f * g\|_{1} \leq\|f\|_{1}\|g\|_{1} \text {. }
$$

Ini berarti $f * g$ ada.

Jadi, konvolusi dari $f$ dan $g$ terdefinisi dengan baik setidaknya untuk beberapa kasus di atas. Lebih jauh, operasi konvolusi memiliki beberapa sifat sebagai berikut.

Lemma 1 (Gunawan, 2017). Misalkan $f, g, h$ adalah fungsi dan a konstan, maka

(i) $f * g=g * f$ (sifat komutatif)

(ii) $f *(g * h)=(f * g) * h \quad$ (sifat asosiatif) 
(iii) $\quad \alpha(f * g)=(a f * g)=f *(a g) \quad$ (sifat distributif).

Berdasarkan sifat di atas, walaupun operasi konvolusi komutatif, salah satu fungsi, sebutlah $g$, dapat dipandang sebagai konvolutor dalam $f * g$. Secara umum, hasil dari $f * g$ adalah suatu fungsi yang lebih mulus daripada $f$ semula.

Selanjutnya, berbeda dengan operasi matematika lainnya, operasi konvolusi tidak memiliki unsur identitas. Andaikan ada unsur identitas, misalkan $e$, maka $f * e=f$ untuk setiap $f \in$ $L^{1}\left(\mathbb{R}^{d}\right)$. Hal ini tidak mungkin terjadi karena bertentangan dengan teorema dan akibat berikut.

Teorema 1 (Gunawan, 2017). Misalkan $f, g \in L^{1}$. Maka $(f * g)^{\wedge}=\hat{f} \hat{g}$.

Bukti. Perhatikan bahwa jika $f \in L^{1}$, maka transformasi Fourier dari $f$, ditulis $\hat{f}$, didefinisikan oleh

$$
\hat{f}(\xi)=\int f(x) e^{-i \xi x} d x, \xi \in \mathbb{R} .
$$

Berdasarkan definisi, Teorema Fubini, dan substitusi peubah $z=x-y$, diperoleh

$$
\begin{aligned}
\widehat{f * g}(\xi) & =\int_{-\infty}^{\infty} \int_{-\infty}^{\infty} f(y) g(x-y) e^{-i \xi x} d y d x \\
& =\int_{-\infty}^{\infty} \int_{-\infty}^{\infty} f(y) e^{-i \xi y} g(x-y) e^{-i \xi(x-y)} d y d x \\
& =\int_{-\infty}^{\infty} \int_{-\infty}^{\infty} f(y) e^{-i \xi y} d y g(z) e^{-i \xi(z)} d z=\hat{f}(\xi) \hat{g}(\xi) .
\end{aligned}
$$

Jadi, terbukti $\widehat{f * g}=\hat{f} \hat{g}$.

Akibat 1 (Gunawan, 2017) Tidak terdapat fungsi $e \in L^{1}\left(\mathbb{R}^{d}\right)$ yang memenuhi $f * e=f$ untuk setiap $f \in L^{1}\left(\mathbb{R}^{d}\right)$.

Bukti. Andaikan ada fungsi $e \in L^{1}\left(\mathbb{R}^{d}\right)$ yang memenuhi $f * e=f$ untuk setiap $f \in L^{1}\left(\mathbb{R}^{d}\right)$, maka $\hat{e}(\xi)=1$ untuk setiap $\xi \in \mathbb{R}^{d}$. Hal ini bertentangan dengan Teorema Riemann-Lebesgue yang mengharuskan $\hat{e}(\xi) \rightarrow 0$ untuk $|\xi| \rightarrow \infty$. Jadi, terbukti bahwa operasi konvolusi tidak memiliki unsur identitas.

Berdasarkan Teorema 1, maka dapat disimpulkan bahwa tidak ada fungsi $e \in L^{1}\left(\mathbb{R}^{d}\right)$ yang memenuhi $f * e=f$ untuk setiap $f \in L^{1}\left(\mathbb{R}^{d}\right)$. Hal ini menunjukkan operasi konvolusi tidak memiliki unsur identitas sebagaimana disebutkan pada Akibat 1. Meskipun demikian, dapat didefinisikan identitas hampiran sebagai berikut.

Definisi 2 (Gunawan, 2017). Misalkan $\phi \in L^{1}(\mathbb{R})$. Untuk setiap $\epsilon>0$, definisikan

$$
\phi_{\epsilon}(x)=\frac{1}{\epsilon} \phi\left(\frac{x}{\epsilon}\right), x \in \mathbb{R}
$$

maka

$$
\int_{-\infty}^{\infty} \phi_{\epsilon}(x) d x=\int_{-\infty}^{\infty} \frac{1}{\epsilon} \phi\left(\frac{x}{\epsilon}\right) d\left(\frac{x}{\epsilon}\right)=\int_{-\infty}^{\infty} \phi(y) d y .
$$


Keluarga fungsi $\left\{\phi_{\epsilon}\right\}$ disebut identitas hampiran.

Dengan demikian, pada operasi konvolusi dapat ditentukan suatu barisan fungsi $g_{k}$ sebagai identitas hampiran sedemikian sehingga $f * g_{k}$ konvergen ke $f$ untuk $k \rightarrow \infty$. Hal ini mengakibatkan operasi konvolusi dapat digunakan untuk memperoleh aproksimasi suatu fungsi. Dalam hal ini, barisan $\left\{g_{k}\right\}$ dipandang sebagai konvolutor pada operasi konvolusi yang dilakukan. Selain di $\mathbb{R}^{d}$, identitas hampiran juga dapat diaplikasikan untuk konvolusi aljabar terukur (Lahr, 1973). Kemudian, Avramidou (2004) juga menggunakan identitas hampiran dan kekonverge nan titik demi titik untuk menginduksi operator konvolusi di ruang $L_{p}(\mathbb{R})$. Dalam penerapannya, konvolutor yang digunakan disesuaikan dengan masalah aproksimasi yang dihadapi. Pemilihan konvolutor yang tidak tepat dapat menjadikan pengolahan menjadi leb ih rumit dan mempengaruhi kecepatan proses komputasi.

Banyak peneliti yang tertarik melakukan penelitian tentang konvolusi, pemilihan konvolutor/kernel, dan masalah aproksimasi lainnya, diantaranya, Shawe-Taylor (2004) membahas mengenai metode-metode kernel untuk analisis pola, Anastassiou (2004) menjelaskan tipe konvolusi operator integral fuzzy, Leila (2007) menggunakan "gelombang meksiko" sebagai fungsi transfer untuk aproksimasi berbagai permasalahan pada berbagai aplikasi dalam fisika, Madden (2004) dan Wu (2009) memfokuskan penelitiannya pada cara pemilihan kernel dan parameter untuk Support Vector Machine (SVM).

Adapun Cheney (2009) membahas mengenai teori-teori aproksimasi, Kahar (2016) menjelaskan mengenai aproksimasi fungsi dengan konvolusi khususnya pengkonstruksian kernel baru tanpa dilasi yang mempunyai support sepanjang $\mathbb{R}^{d}$, Paul-Escande (2017) menganalisis teknik yang disebut ekspansi konvolusi produk, yakni operator (integral operator) didekati secara lokal oleh konvolusi yang memungkinkan untuk merancang algoritma numerik cepat berdasarkan transformasi Fourier, Xu (2018) mengembangkan framework untuk mengkonstruksi aproksimasi matriks ke operator konvolusi Volterra, Bhaya (2019) menggunakan fungsi radial untuk aproksimasi fungsi di ruang L $p$ untuk $p<1$, dan Gao et.al. (2020) membahas mengenai algoritma untuk aproksimasi sumof-exponentials (SOE) dari fungsi kernel dan mengembangkan algoritma cepat untuk konvolusi kuadratur berdasarkan SOE.

Kajian lebih mendalam terhadap aproksimasi fungsi dengan konvolusi diperlukan untuk dapat mengkonstruksi konvolutor/kernel baru yang dapat digunakan untuk aproksimasi fungsi. Oleh karena itu, pada artikel ini dibahas mengenai aproksimasi fungsi dengan konvolusi dengan mengkonstruksi kernel/konvolutor khususnya untuk fungsi-fungsi kontinu terbatas di $\mathbb{R}^{d}$ dengan menggunakan norm $\|.\|_{1}$ dan $\|.\|_{\infty}$.

\section{METODE}

Penelitian ini dimulai dengan studi literatur, yakni dengan mencari referensi teori yang relevan dengan kasus atau permasalahan yang sedang dibahas. Kemudian dilakukan pengkajian hasil studi literatur untuk membuktikan teorema-teorema serta contoh yang berkaitan masalah aproksimasi fungsi dengan konvolusi terbatas di $\mathbb{R}^{d}$ dengan menggunakan norm $\|$. $\|_{1}$. Lebih lanjut, dibuktikan pula aproksimasi fungsi kontinu terbatas dengan $\|.\|_{\infty}$. 


\section{HASIL DAN PEMBAHASAN}

Telah disebutkan bahwa operasi konvolusi tidak memiliki unsur identitas. Namun, operasi konvolusi memiliki identitas hampiran, yakni dapat ditemukannya suatu barisan fungsi $g_{k}$ sehingga konvolusi dari $f$ dan $g_{k}$ konvergen ke $f$ untuk $k \rightarrow \infty$. Hal ini mengakibatkan konvolusi dapat digunakan untuk aproksimasi fungsi.

Selanjutnya, hal yang mendasari bagaimana konvolusi dapat digunakan untuk mengaproksimasi suatu fungsi disajikan pada Teorema 2. Teorema tersebut analog dengan Folland (1992), Cheney (2009), dan Kahar (2016).

Teorema 2. Misalkan $H_{1}, H_{2}, \ldots$ merupakan suatu barisan di $L^{1}\left(\mathbb{R}^{d}\right)$ sedemikian sehingga $\sup _{k}\left\|H_{k}\right\|_{1}<\infty$ dan $\int_{\mathbb{R}^{d}} H_{k}(x) d x=1$ untuk setiap $k$. Asumsikan juga bahwa untuk sebarang $\delta>0$ berlaku

$$
\lim _{k \rightarrow \infty} \int_{\|x\|>\delta}\left|H_{k}(x)\right| d x=0 .
$$

Kemudian, untuk setiap fungsi terbatas $f \in C\left(\mathbb{R}^{d}\right)$,

$$
H_{k} * f \rightarrow f
$$

dan kekonvergenannya seragam pada himpunan kompak di $\mathbb{R}^{d}$.

Bukti. Ambil sebarang fungsi terbatas $f \in C\left(\mathbb{R}^{d}\right)$. Akan dibuktikan $H_{k} * f \rightarrow f$ untuk $k \rightarrow \infty$. Karena $\int_{\mathbb{R}^{d}} H_{k}(x) d x=1$, maka

$$
\begin{aligned}
\left|\left(H_{k} * f\right)(x)-f(x)\right| & =\left|\int H_{k}(y) f(x-y) d y-f(x) \int H_{k}(y) d y\right| \\
& =\left|\int H_{k}(y)[f(x-y)-f(x)] d y\right| \\
& \leq \int\left|H_{k}(y)\right||f(x-y)-f(x)| d y .
\end{aligned}
$$

Selanjutnya, ambil sebarang $\varepsilon>0$ definisikan bola- $r$ dengan pusat di 0 dan berjari-jari $r$ sebagai

$$
B_{r}=\left\{x \in \mathbb{R}^{d}:\|x\| \leq r\right\}
$$

dan karena $f$ kontinu, pilih $\delta>0$ yang cukup kecil sedemikian sehingga

$$
|f(x-y)-f(x)|<\varepsilon / 2
$$

untuk $0<\|y\|<\delta$.

Perhatikan

Sekarang, tinjau $I_{1}$.

$$
\begin{aligned}
& \left|H_{k} * f(x)-f(x)\right| \leq \int_{B_{r}}\left|H_{k}(y)\right||f(x-y)-f(x)| d y \\
& +\int_{\mathbb{R}^{\mathrm{d}} \backslash \mathrm{B}_{\mathrm{r}}}\left|H_{k}(y)\right||f(x-y)-f(x)| d y=I_{1}+I_{2} .
\end{aligned}
$$

$$
I_{1}=\int_{B_{r}}\left|H_{k}(y)\right||f(x-y)-f(x)| d y \leq \varepsilon / 2 \int_{B_{r}} H_{k}(y) d y \leq \varepsilon / 2 .
$$


Kemudian tinjau $I_{2}$. Karena $f$ terbatas, terdapat $M$ sedemikian sehingga $|f|<M$, maka

$$
\begin{aligned}
I_{2} & =\int_{\mathbb{R}^{d} \backslash B_{r}}\left|H_{k}(y)\right||f(x-y)-f(x)| d y \leq \int_{\mathbb{R}^{d} \backslash B_{r}}\left|H_{k}(y)\right|[|f(x-y)|+|f(x)|] d y \\
& =2 M \int_{\mathbb{R}^{d} \backslash B_{r}}\left|H_{k}(y)\right| d y .
\end{aligned}
$$

Karena $\lim _{k \rightarrow \infty} \int_{\|y\|>\delta}\left|H_{k}(y)\right| d y=0$, akibatnya $I_{2} \rightarrow 0$ untuk $k \rightarrow \infty$.

Karena $I_{1} \rightarrow 0$ dan $I_{2} \rightarrow 0$ untuk $k \rightarrow \infty$, maka dapat disimpulkan bahwa untuk $k \rightarrow \infty, \mid H_{k} *$ $f x-f(x) \rightarrow 0$. Selanjutnya, kekonvergenannya seragam karena $f$ terletak pada himpunan kompak di $\mathbb{R}$.

Selanjutnya, dalam hal pemilihan konvolutor untuk aproksimasi fungsi, pada Teorema 2 disebutkan bahwa konvolutor memiliki sifat-sifat tertentu. Salah satu cara mengkonstruksi konvolutor tersebut adalah dengan melakukan dilasi pada suatu kernel. Perhatikan Lemma 2.

Lemma 2. Misalkan $H \in L^{1}\left(\mathbb{R}^{d}\right)$. Didefinisikan $H_{k}(x)=k^{d} H(k x)$ sedemikian sehingga $\int_{\mathbb{R}^{d}} H_{k}(x) d x=1$ dengan $k \in \mathbb{N}$ dan $x \in \mathbb{R}^{d}$. Maka

$$
\int_{\mathbb{R}^{d}} H_{k}(x) d x=\int_{\mathbb{R}^{d}} H(x) d x,\left\|H_{k}\right\|_{1}=\|H\|_{1}
$$

dan

$$
\lim _{k \rightarrow \infty} \int_{\mathbb{R}^{d} \backslash B(0, r)}\left|H_{k}(x)\right| d x=0
$$

untuk setiap $r>0$.

Bukti. Tulis $z=k x$ maka

$$
\int_{\mathbb{R}^{d}} H_{k}(x) d x=\int_{\mathbb{R}^{d}} k^{d} H(k x) d x=\int_{\mathbb{R}^{d}} k^{d} H(z) \frac{1}{k^{d}} d z=\int_{\mathbb{R}^{d}} H(z) d z .
$$

Kemudian

$$
\left\|H_{k}\right\|_{1}=\int_{\mathbb{R}^{d}} H_{k}(x) d x=\int_{\mathbb{R}^{d}} H(z) d z=\|H\|_{1} .
$$

Selanjutnya, dengan menggunakan Teorema Kekonvergenan Terdominasi Lebesgue, maka

$$
\begin{aligned}
\int_{\mathbb{R}^{d} \backslash B(0, r)}\left|H_{k}(x)\right| d x & =k^{d} \int_{\mathbb{R}^{d} \backslash B(0, r)}|H(k x)| d x=\int_{\mathbb{R}^{d} \backslash B(0, k r)}|H(z)| d z \\
& =\int_{\mathbb{R}^{d} \backslash B(0, k r)} H(z) \chi_{\mathbb{R}^{d} \backslash B(0, k r)} d z \rightarrow 0
\end{aligned}
$$

untuk $k \rightarrow \infty$.

Barisan fungsi $H_{k}$ yang didefinisikan pada Lemma 2 di atas memenuhi sifat yang serupa dengan identitas hampiran, sehingga barisan fungsi tersebut dapat dijadikan ko nvolutor untuk aproksimasi fungsi. Lebih lanjut, konvolutor yang diperoleh dari dilasi suatu kernel harus memenuhi sifat seperti yang disebutkan pada Lemma 2. Selanjutnya, kekonvergenan dari operasi konvolusi menjadi hal utama yang dibicarakan pada penelitian ini. 
Teorema 3. Misalkan fungsi $H$ memenuhi Lemma 2. Misalkan pula $H_{k}$ merupakan dilasi dari kernel $H$. Maka untuk setiap fungsi kontinu terbatas $f$ yang terdefinisi pada $\mathbb{R}^{d}$ berlaku

$$
H_{k} * f \rightarrow 0
$$

untuk $k \rightarrow \infty$ dan kekonvergenannya seragam pada himpunan kompak di $\mathbb{R}^{d}$.

Bukti. Ambil sebarang fungsi terbatas $f \in C\left(\mathbb{R}^{d}\right)$. Karena $\int_{\mathbb{R}^{d}} H_{k}(x) d x=1$ maka

$$
\begin{aligned}
\left|\left(H_{k} * f\right)(x)-f(x)\right| & =\left|\int H_{k}(y) f(x-y) d y-f(x)\right| \\
& =\left|\int H_{k}(y)[f(x-y)-f(x)] d y\right| \\
& \leq \int\left|H_{k}(y)\right||f(x-y)-f(x)| d y .
\end{aligned}
$$

Ambil $\varepsilon>0$. Karena $f$ kontinu, maka terdapat $r>0$ sedemikian sehingga untuk $\|y\| \leq r$ berlaku $f(x-y)-f(x)<\frac{\varepsilon}{2\|H\|_{1}}$. Selanjutnya, tulis

$$
\begin{aligned}
& \qquad\left|H_{k} * f(x)-f(x)\right| \\
& \leq \int_{B_{r}}\left|H_{k}(y)\right||f(x-y)-f(x)| d y+\int_{\mathbb{R}^{\mathrm{d}} \backslash \mathrm{B}_{\mathrm{r}}}\left|H_{k}(y)\right||f(x-y)-f(x)| d y \\
& =I_{1}+I_{2} .
\end{aligned}
$$

Sekarang, tinjau $I_{1}$.

$$
I_{1}=\int_{B_{r}}\left|H_{k}(y)\right||f(x-y)-f(x)| d y \leq \frac{\varepsilon}{2\|H\|_{1}} \int_{B_{r}} H_{k}(y) d y \leq \varepsilon / 2 .
$$

Kemudian tinjau $I_{2}$. Karena $f$ terbatas, terdapat $M$ sedemikian sehingga $|f|<M$, maka

$$
\begin{aligned}
I_{2}= & \int_{\mathbb{R}^{d} \backslash B_{r}}\left|H_{k}(y)\right||f(x-y)-f(x)| d y \leq \int_{\mathbb{R}^{d} \backslash B_{r}}\left|H_{k}(y)\right|[|f(x-y)|+|f(x)|] d y \\
& =2 M \int_{\mathbb{R}^{d} \backslash B_{r}}\left|H_{k}(y)\right| d y \rightarrow 0
\end{aligned}
$$

sehingga terdapat $N \in \mathbb{N}$ sedemikian sehingga untuk $k>N$ berlaku

$$
\left|H_{k} * f(x)-f(x)\right|<\varepsilon
$$

Selanjutnya, kekonvergenannya seragam karena $f$ terletak pada himpunan kompak di $\mathbb{R}$.

Teorema 3 menyatakan bahwa konvolutor hasil dilasi dapat digunakan untuk aproksimasi fungsi. Hal serupa juga dikemukakan Cheney (2009) dan Kahar (2016). Lebih jauh lagi, Cheney (2009) dan Kahar (2016) memberikan beberapa contoh kernel hasil dilasi. Berikut ini salah satu contoh dilasi dari kernel $H$ yang memenuhi Teorema 3. 
Contoh 1. Misalkan

$$
H_{k}(x)=\left\{\begin{array}{lr}
c_{k}\left(1-\|x\|^{2}\right)^{k}, & \text { untuk }\|x\| \leq 1 \\
0, & \text { untuk }\|x\|>1
\end{array} .\right.
$$

dengan $\|x\| \in \mathbb{R}^{d},\|$.$\| menyatakan norm Euclid, dan c_{k}$ konstanta yang dipilih sedemikian sehingga $\int_{\mathbb{R}^{d}} H_{k}(x) d x=1$. Akan ditunjukkan $\lim _{\mathrm{k} \rightarrow \infty} \int_{\|\mathrm{x}\|>\delta}\left|H_{k}(x)\right| d x=0$. Ambil $\delta>0$. Jika $\delta>1$, berdasarkan definisi, integran $H_{k}(x)$ sama dengan nol untuk $\|x\|>\delta$ sehingga

$$
\int_{\|x\|>\delta}\left|H_{k}(x)\right| d x=0 .
$$

Selanjutnya, asumsikan $0<\delta \leq 1$. Definisikan bola satuan $\mathcal{S}^{d-1}$ di $\mathbb{R}^{d}$ sebagai

$$
\mathcal{S}^{d-1}=\left\{x \in \mathbb{R}^{d}:\|x\|_{2}=1\right\}
$$

dan nyatakan $\omega_{d-1}$ sebagai daerah berdimensi $d$ dari $\mathcal{S}^{d-1}$. Kemudian, gunakan koordinat polar, maka untuk $\rho \in(0,1)$

diperoleh

$$
\begin{aligned}
c_{k}^{-1} & =\int_{\|x\| \leq 1}\left(1-\|x\|^{2}\right)^{k} d x=\omega_{d-1} \int_{0}^{1}\left(1-r^{2}\right)^{k} r^{d-1} d r \\
& \geq \omega_{d-1} \int_{0}^{p}\left(1-r^{2}\right)^{k} r^{d-1} d r \geq\left(1-\rho^{2}\right)^{k} \omega_{d-1} \int_{0}^{p} r^{d-1} d r \\
& =\left(1-\rho^{2}\right)^{k} \omega_{d-1} \rho^{d} / d
\end{aligned}
$$

sehingga

$$
c^{k} \leq d\left(1-\rho^{2}\right)^{-k} \rho^{-d} \omega_{d-1}^{-1}
$$

$$
\begin{aligned}
\int_{\|x\|>\delta}\left|H_{k}(x)\right| d x & =\int_{\|x\|>\delta}\left|c_{k}\left(1-\|x\|^{2}\right)^{k}\right| d x=\omega_{d-1} \int_{\delta}^{1} c_{k}\left(1-r^{2}\right)^{k} r^{d-1} d r \\
& \leq \omega_{d-1} c_{k}\left(1-\delta^{2}\right)^{k} \int_{\delta}^{1} r^{d-1} d r \\
& \leq \omega_{d-1} c_{k}\left(1-\delta^{2}\right)^{k} \int_{0}^{1} r^{d-1} d r \\
& \leq \omega_{d-1} d\left(1-\rho^{2}\right)^{-k} \rho^{-d} \omega_{d-1}^{-1}\left(1-\delta^{2}\right)^{k} d^{-1} \\
& =\left(\frac{1-\delta^{2}}{1-\rho^{2}}\right)^{k} \rho^{-d} .
\end{aligned}
$$

Pilih $\rho$ sehingga $0<\rho<\delta$ maka $\left(\frac{1-\delta^{2}}{1-\rho^{2}}\right)^{k} \rho^{-d} \rightarrow 0$ untuk $k \rightarrow \infty$. Dengan demikian, terbukti bahwa $\int_{\|\mathrm{x}\|>\delta}\left|H_{k}(x)\right| d x \rightarrow 0$ untuk $k \rightarrow \infty$. 
Dengan demikian barisan $H_{k}$ yang didefinisikan seperti pada Contoh 1 dan memenuhi sifatsifat seperti yang disebutkan pada Teorema 2 dan Teorema 3 dapat digunakan sebagai identitas hampiran pada konvolusi. Akibatnya, untuk setiap fungsi $f$ yang kontinu terbatas dan terdefinisi pada $\mathbb{R}^{d}$, konvolusi dari $f * H_{k}$ merupakan hasil aproksimasi fungsi tersebut.

Perhatikan bahwa pada Teorema 2 dan 3, aproksimasi fungsi kontinu terbatas dilakukan dengan menggunakan norm-1. Selanjutnya, akan ditunjukkan bahwa aproksimasi fungsi kontinu terbatas juga dipenuhi untuk norm $\|.\|_{\infty}$.

Teorema 4. Misalkan $p \in[1, \infty), \phi \in L^{1}\left(\mathbb{R}^{d}\right), a=\int_{\mathbb{R}^{d}} f(x) d x$, dan untuk $t>0$ misalkan $\phi_{t}(x)=\frac{1}{t} \phi\left(\frac{x}{t}\right)$. Jika $f$ fungsi kontinu terbatas di $\mathbb{R}^{d}$ dan $f$ kontinu seragam maka $\| \phi_{t} * f-$ af $\infty$ konvergen ke 0 untuk $t \rightarrow 0$.

Bukti. Misalkan $y=t z$ maka

sehingga

$$
\phi * f(x)=\int_{\mathbb{R}^{d}} f(x-y) \phi_{t}(y) d y=\int_{\mathbb{R}^{d}} f(x-t z) \phi(z) d z
$$

$$
\phi * f(x)-a f(x)=\int_{\mathbb{R}^{d}}[f(x-t z)-f(x)] \phi(z) d z=\int_{\mathbb{R}^{d}}\left[\tau_{t z} f(x)-f(x)\right] \phi(z) d z .
$$

Kemudian,

$$
\left\|\phi_{t} * f-a f\right\|_{\infty} \leq \int_{\mathbb{R}^{d}}\left\|\tau_{t z} f-f\right\|_{\infty}|\phi(z)| d z .
$$

Karena $f$ kontinu seragam maka $\lim _{t \rightarrow 0}\left\|\tau_{t z} f-f\right\|_{\infty}=0$ secara seragam. Dengan menggunakan Teorema Kekonvergenan Terdominasi mengakibatkan

$$
\int_{\mathbb{R}^{d}}\left\|\tau_{t z} f-f\right\|_{\infty}|\phi(z)| d z \rightarrow 0 .
$$

Karena (40) dan (41), maka $\left\|\phi_{t} * f-a f\right\|_{\infty} \rightarrow 0$ untuk $t \rightarrow 0$.

\section{SIMPULAN}

Konvolusi merupakan operasi matematika pada dua fungsi yang menghasilkan suatu fungsi baru dan dapat dipandang sebagai versi modifikasi dari salah satu fung si aslinya. Operasi konvolusi memiliki identitas hampiran. Hal ini yang mendasari konvolusi dapat digunakan untuk aproksimasi fungsi termasuk fungsi-fungsi kontinu terbatas. Misalkan $H_{k}$ barisan fungsi yang memenuhi sifat tertentu, maka untuk setiap fungsi kontinu terbatas $f$ yang terdefinisi di $\mathbb{R}^{d}$, kekonvergenan $f * H_{k}$ seragam pada himpunan kompak di $\mathbb{R}^{d}$ pada norm-1. Lebih lanjut, telah dibuktikan aproksimasi fungsi kontinu terbatas pada norm $\|.\|_{\infty}$.

Selanjutnya, berdasarkan hasil tersebut, dapat dicari pula konvolutor untuk aproksimasi fungsi-fungsi lain seperti fungsi di ruang Lebesgue $\left(L^{p}\right)$ dengan $1 \leq p \leq \infty$ dan kaitannya antara fungsi kontinu seragam dengan fungsi terukur Lebesgue. Selain itu, dapat dikaji pula penerapan konvolutor yang telah dikontruksi pada pengolahan citra digital.

\section{UCAPAN TERIMA KASIH}

Penulis mengucapkan terima kasih kepada Lembaga Pusat Penelitian dan Pengabdian Masyarakat Universitas Terbuka yang telah mendanai penelitian mengenai aproksimasi fungsi dan penerapannya pada pengolahan citra digital. Artikel ini merupakan salah satu luaran dari penelitian tersebut. 


\section{REFERENSI}

Anastassiou. (2004). Fuzzy approximation by fuzzy convolution type operators. Elsevier: Computers and Mathematics with Applications, 48, 1369-1386.

Avramidou, P. (2004). Convolution operators inducted by approximate identities and pointwise convergence in Lp (R) spaces. Proceedings of American Mathematical Society, 175-184.

Bhaya, S. E. (2019). Approximation of function in Lp spaces for $p<1$ using radial basis function neural network. Journal of University of Babylon for Pure and Applied Sciences, 27(3), 400-405.

Cheney, W. L. (2009). A Course in Approximation Theory. United State: American Mathematical Society.

Folland, G. (1992). Fourier Analysis and Its Application. California: Wadswoth \& Brooks/Cole Advanced Book \& Sofware.

Gao, Z. Liang, J. \&. Xu, Z. (2020). Kernel-independent sum-of-exponentials with application to convolution quadrature. arXiv:2012.13477v1 [math.NA].

Gunawan, H. (2017). Analisis Fourier dan Wavelet. Bandung: FMIPA ITB.

Kahar, E. R. (2016). Aproksimasi Fungsi dengan Konvolusi. Bandung: (Tesis ITB) Tidak diterbitkan.

Lahr, C. D. (1973). Approximate identities for convolution measure algebra. Pasific Journal of Mathematics, 47(1), 147-159.

Leila, A. G.-C. (2007). Function approximation of tasks by neural networks. Conference Paper: 6th Conference on Nuclear and Particle Physics.

Madden, M. G. (2004). The genetic evolution of kernel for support vector machine classifiers. Proceeding of AICS 2004, 15th Irish Conference on Artificial Intelligence and Cognitive Science.

Paul-Escande, P. W. (2017). Approximation of integral operators using product-convolution expansions. Journal of Mathematical Imaging and Vision, Springer Verlag, 58 (3), pp.333348.

Shawe-Taylor, J. (2004). Kernel Methods for Pattern Analysis. Cambridge: Cambridge University Press. doi:10.1017/CB09780511809682.

Stein, E. M. (2003). Fourier Analysis: An Introduction. New Jersey: Princeton University Press.

Wu, K.-P. \& Wang S-D. (2009). Choosing the kernel parameters for support vector machines by the inter-cluster distance in the feature space. Pattern Recognition.42, 710-717.

$\mathrm{Xu}, \mathrm{K}$. (2018). Spectral approximation of convolution operators. SIAM Journal on Scientific Computing, 40.10. 1137/17M1149249. 